\title{
0 Direito brasileiro no mundo globalizado: os desafios do Poder Judiciário ao promover o bem estar social e os direitos humanos em suas decisões
}

https://doi.org/10.21814/uminho.ed.30.17

\author{
Karine Somavilla Manfio \\ Bacharel em Direito pela Universidade Franciscana/ Brasil \\ e Pós-Graduanda em Direito dos Contratos e Consumo pela \\ Universidade de Coimbra
}

\section{Introdução}

O presente trabalho objetiva analisar a jurisdição brasileira no contexto de um mundo globalizado, os seus desafios como promotora do bem estar social do país, levando em consideração cada vez mais os direitos humanos nas suas decisões. Essa temática aborda a questão de como pode ser conectada a tutela jurisdicional de um direito de bem estar social ao desenvolvimento económico do Brasil.

É sobre essa problemática que versa a presente investigação. Elaborado a partir de um método de procedimento monográfico utilizando doutrinas, leis e decisões judiciais, bem como, a aplicação de um método de abordagem dedutivo, visto que a investigação se dará a partir de uma norma geral para o caso concreto.

A aplicação desse método resultou na divisão do trabalho em três partes: primeiramente analisar as diversas vertentes sobre o tema globalização, pois esta afeta as influências internacionais, devido à informatização, comunicação, transcendendo fronteiras.

No segundo momento, apresentamos a tarefa do poder judiciário brasileiro em efetivar os direitos sociais e assegurar os direitos humanos para garantir aos cidadãos à dignidade humana, o mínimo existencial, a saúde, a educação, o lazer, entre outros, elencados no artigo $6^{\circ}$ da Constituição da República Federativa do Brasil de 1988.

Por fim, verificar que o Estado não atua apenas como prestacionista de direitos, ele também deve concretizá-los. Nesse sentido, é imprescindível a análise de quatro decisões que fomentam a prestação jurisdicional dos direitos sociais e à isonomia material. 


\section{Desenvolvimento}

Inicialmente, cabe salientar que a globalização, cuja língua portuguesa entende ser um processo económico e político que visa a integração entre economias e mercados de diferentes países, está intrinsecamente ligada nos dias atuais a tudo que nos cerca. Porém, mais do que apenas um método económico e político, encontram-se o viés social e cultural, o qual faz permitir que direitos sejam reconhecidos universalmente.

Dessa maneira, o efeito da globalização na esfera jurídica introduz direitos traduzidos como de igualdade, dando inicio à fase de um estado social. Recepcionados pela Constituição da República Federativa do Brasil de 1988, os direitos económicos, sociais e culturais, devem ser ao máximo assegurados, para que seja possível garantir a sua concretização. Aos olhos de Cordeiro ${ }^{1}$, o Estado deve garantir aos seus membros, um padrão de vida minimamente decente, atendendo ao direito à educação, à saúde, à alimentação, ao trabalho, à moradia, ao transporte, ao lazer, à segurança, à previdência social, à proteção à maternidade e à infância, à assistência aos desamparados, entre outros, positivados no seu Artigo 6. ${ }^{\circ 2}$. Conforme Carvalho, "é preciso entender o direito de bem estar, como direito de cunho coletivo, no sentido de, embora passível de apropriação individual, interessar à coletividade, razão de sua classificação como público"’.

É nesse contexto que além de possuir positivação e de ser prestacionado pelo Estado, o Poder Judiciário deve encontrar espaços para concretizar em todas as decisões valores constitucionais. Bem como, deve resguardar valor à dignidade da pessoa humana, considerada como um valor absoluto da natureza racional e como critério de construção de identidade de cada sujeito, preocupando-se com o bem estar, premissa deste Estado.

Dessa forma, como pode ser conectada a tutela jurisdicional de um direito de bem estar social atrelada com o desenvolvimento econômico do Brasil, sendo atribuição de um Estado prestacionista proteger o direito de bem estar, por um lado, e efetivar tais direitos pela jurisdição, de outro. Entende Carvalho ${ }^{4}$ que a atividade jurisdicional deve praticar uma conduta construtiva e comprometida com a construção da efetividade dos conteúdos dispostos no ordenamento com a proteção dos valores tutelados, não apenas com o objetivo de fornecer de modo formal, mas sim de se implementar.

1 CORDEIRO, Karine da Silva - Direitos Fundamentais Sociais: Dignidade da Pessoa humana e mínimo existencial - O papel do Poder Judiciário. Porto Alegre, RS: Livraria do Advogado, 2012, p. 94.

2 Constituição da República Federativa do Brasil de 1988, Art. 60: "São direitos sociais a educação, a saúde, a alimentação, o trabalho, a moradia, o transporte, o lazer, a segurança, a previdência social, a proteção à maternidade e à infância, a assistência aos desamparados, na forma desta Constituição".

3 CARVALHO, Morgana Bellazzi de Oliveira - Jurisdição no Estado do Bem estar e do desenvolvimento. Dissertação (Mestrado em Direito), Salvador: Universidade Federal da Bahia, 2008, p. 154.

4 Idem, p. 156. 
Assim, o Judiciário deve definir os parâmetros e caminhos para a efetivação dos direitos na vida real, atuando como co-gestor. É o que se vem notando, na participação do Judiciário na realização de politicas públicas em toda a seara nacional, em habitação - a Lei Federal 10.257 de 2001 (Estatuto da Cidade), a Lei Federal 13.465 de 2017 (Regularização Fundiária Urbana), Lei Federal 11.977 de 2009 (Programa Minha Casa Minha Vida); na área da saúde - o SUS (Sistema Único de Saúde); em assistência social - a Politica Nacional de Assistência Social (PNAS-2004); em segurança - a Política Nacional de Segurança Pública (PNaSP); em educação - o programa de Educação para Jovens e Adultos (EJA); Programa Universidade Para Todos (PROUNI), Fundo de Manutenção e Desenvolvimento da Educação Básica (FUNDEB), entre outras.

Não obstante a promoção dos direitos acima referidos, o direito brasileiro guarda segurança ao princípio da igualdade ou isonomia material, ao procurar tratar os desiguais na medida das suas desigualdades, ao passo que o Direito tem a função de oferecer um recurso diferenciado que assegure a igualdade. Dessa forma, mais uma vez, o Judiciário entra como precursor de uma garantia humana estabelecendo proteção e garantindo a efetividade de direitos em suas decisões. Abarcados por esse princípio, esclarece Sarlet: "estes direitos fundamentais caracterizam-se, por outorgarem ao indivíduo, direitos a prestações sociais estatais, como assistência social, saúde, educação, trabalho, etc., revelando uma transição das liberdades formais abstratas para as liberdades materiais concretas. [...] Estes direitos fundamentais, no que se distinguem dos clássicos direitos de liberdade e igualdade forma nasceram abraçados ao princípio da igualdade, entendida esta num sentido material"5.

Deste modo, os direitos aqui referidos encontram-se em harmonia e são compreendidos como parte de um todo. Pois, da mesma forma que ocorre com os direitos sociais, a igualdade material para ser alcançada plenamente depende de prestação do Estado. Isso vem sendo concretizado pelas ações afirmativas, ou seja, são políticas públicas que buscam a igualdade de oportunidade para todos, como é o caso da destinação de vagas em diversos níveis de ensino concursos públicos para pessoas com deficiência, negros, pardos, índios, e baixa renda, bem como, reserva de vagas prioritárias em programas de habitação, estímulo à contratação de indivíduos de grupos sociais discriminados, entre outras.

Diante do exposto, essa postura do Judiciário em controlar os atos do poder público gera efetividade, pois a sociedade reconhece que os direitos de bem estar, sejam eles coletivos ou individuais, se cumprem com a segurança jurídica, e acabam por se ampliar.

Assim, a tarefa do Poder Judiciário em efetivar os direitos sociais e a isonomia material não apenas fica a mercê de políticas públicas, também se concretizam diante das decisões emanadas pelos órgãos judiciais.

5 SARLET, Ingo Wolfgang - Constitucionalismo e democracia. Porto Alegre: Livraria do Advogado, 2001, p. 51. 
Demonstrada a importância da investigação, a escolha dos casos deu-se por meio de pesquisa jurisprudencial, nos sites Tribunal de Justiça de Minas Gerais e Tribunal de Justiça do Rio Grande do Sul, sendo que foram pesquisadas as palavras chaves "REURB" e "saúde". Desse modo serão analisados, um Agravo de Instrumento de $n^{\circ}$ 0862305-96.2013.8.13.0000 e uma Apelação de $n^{\circ} 70084748730$ relativas às politicas públicas de habitação e saúde, respectivamente. Assim como, procedeu-se a pesquisa nos sites do Tribunal de Justiça do Distrito Federal e Territórios e do Tribunal Regional do Trabalho da $17^{a}$ Região, as quais foram pesquisadas as palavras chaves "isonomia material" " "igualdade material". Dessa forma, serão analisados um Recurso Inominado de $n^{\circ}$ 0701005-97.2017.8.07.0018 e um Recurso Ordinário de $n^{\circ}$ 0160700-92.2012.5.17.0013 relativos à isonomia material, respectivamente.

O primeiro caso a ser abordado versa sobre um recurso de Agravo de Instrumento de $n^{\circ}$ 0862305-96.2013.8.13.0000, proveniente da comarca de Belo Horizonte/MG, julgado em 27 de julho de 2014, pela $6^{\text {a }}$ Câmara Cível do Tribunal de Justiça de Minas Gerais, sob a relatoria da desembargadora Sandra Fonseca ${ }^{6}$. A parte agravante - Defensoria Pública do Estado de Minas Gerais - inconformada com a decisão que indeferiu o pedido de liminar para a concessão de viabilização de programa de plano global para a regularização fundiária da Vila Acaba Mundo, interpôs agravo de instrumento para a concessão da referida liminar.

Esclarecendo os factos, em apertada síntese, a ação originária (Ação Civil Pública) tem a finalidade de regularizar uma área de aglomeração de baixa renda consolidada desde 1930, denominada Vila Acaba Mundo. Ocorre que, em 2009, o poder executivo da cidade de Belo Horizonte editou o Decreto Municipal no 13.519/2009 declarando o interesse social e a utilidade pública para fins de desapropriação de 19 lotes correspondentes a moradia de 71 famílias, sem adotar as medidas pertinentes para a regularização fundiária dos imóveis. Dessa forma, requer a ora agravante o direito à moradia em observância a função social da propriedade, bem como, da referida regularização da área.

A relatora fundamentou a presente decisão no sentido de preservar o princípio da dignidade da pessoa humana por meio do direito à moradia às pessoas de baixa renda, eis que cumprida por eles a função social da área. Transcreve-se o presente parâmetro da relatora, "[...] por constituir-se como direito essencial a alcançar os objetivos do Estado Democrático de Direito e pressuposto de existência dos fundamentos deste, o direito à moradia digna deve atuar como instrumento norteador de todo e qualquer programa habitacional e de erradicação da pobreza a ser adotado pelos entes públicos" (fl.5), dependendo de politica pública de urbanização e regularização por meio de medida administrativa a ser realizada pelo ente municipal (fl. 6).

6 Agravo de Instrumento de $\mathrm{n}^{\circ}$ 0862305-96.2013.8.13.0000. [consultado em 2021-04-30]. Disponível na WWW: https://www5.tjmg.jus.br/jurisprudencia/pesquisaNumeroCNJEspelhoAcordao.do; jsessionid=C77814B\%20DD013D9BC6EE1BFB966F779B8. juri_node2? numeroRegistro=1 \& totalLinhas $=1$ \& linhasPorPagina $=1 \% 200$ \& numeroUnico $=0862305$ -96.2013.8.13.0000\&pesquisaNumeroCNJ=Pesquisar. 
Por fim, ressaltou que "a requerida regularização fundiária da região, em princípio, é procedimento complexo, que demanda a atuação integrada de diversos órgãos públicos do Poder Executivo Municipal, e, inclusive do Poder Legislativo" (fl.9), mantendo a decisão do juízo originário, ao passo que deve ser aguardada a completa instrução processual do feito.

Demonstra-se assim, que o Poder Judiciário deve intervir, caso haja necessidade, por meio de decisões, ou por meio de políticas públicas de interesse social, a fim de que sejam asseguradas as garantias fundamentais dos cidadãos, proteger os direitos de bem estar social.

O próximo caso a ser analisado trata-se de um recurso de Apelação de $n^{\circ} 70084748730$ proveniente da comarca de Santa Maria/RS, julgado em 21 de janeiro de 2021, pela $22^{\text {a }}$ Câmara Cível do Tribunal de Justiça do Rio Grande do Sul, sob a relatoria do desembargador Miguel Ângelo da Silva ${ }^{7}$. A parte apelante, inconformada com a sentença que julgou extinto o processo interpôs o recurso para que seja fornecida internação em caráter de urgência em unidade de tratamento intensivo (UTI) à autora em decorrência de acidente vascular cerebral, reconhecendo a solidariedade dos entes da federação no que se refere à saúde.

Em sua fundamentação, o relator motivou-a pelo direito ao acesso à saúde incumbindo o poder judiciário sanar com decisão judicial o cumprimento das prestações contidas nas politicas públicas, "[...] o exame da suficiência das políticas públicas, inclusive das alusivas à saúde pública e correspondentes prestações, não escapa da apreciação casuística do Poder Judiciário, quando chamado a decidir acerca de postulações individualizadas. E há de atuar, em situações tais, com o escopo de assegurar o conteúdo mínimo de proteção que o direito fundamental de acesso à saúde exige" (fl.10). Dessa forma, o recurso foi provido para prosseguir o feito.

Diante do exposto, demonstra-se que não basta apenas que o Estado reconheça em sua Constituição o direito, ele deve garantir e respeitar integralmente esse bem indisponível, dando acesso à assistência médico-hospitalar de forma universal e igualitária.

Merece atenção os dois últimos casos escolhidos para a presente investigação referentes à isonomia material. 0 primeiro caso destina-se a um Recurso Inominado de n 0701005-97.2017.8.07.0018 proveniente da comarca de Brasília, julgado em 07 de março de 2018 pela $2^{\text {a }}$ Turma Recursal do Juizado Especial da Fazenda Pública do Tribunal de Justiça do Distrito Federal e Territórios, sob relatoria do Desembargador Edilson Enedino das Chagas ${ }^{8}$. A demanda originária reconheceu o direito da parte autora (mulher) a permanecer em concurso para cargo de Perito Criminal da Carreira de Polícia Civil do Distrito Federal, por conta de ilegalidade de teste de capacidade física.

7 Apelação de $n^{\circ}$ 70084748730. [consultado em 2021-04-30]. Disponível na WWW: <https://www.tjrs. jus.br/buscas/jurisprudencia/exibe_html.php>.

8 Recurso Inominado $n^{\circ}$ 0701005-97.2017.8.07.0018. [consultado em 2021-04-30]. Disponível na WWW: <https://pesquisajuris.tjdft.jus.br/IndexadorAcordaos-web/sistj>. 
O relator asseverou que "no caso em análise, cerca de 168 homens e 72 mulheres realizaram o teste de aptidão física. Deste total de homens, houve reprovação de 2 candidatos, o que equivaleria a pouco mais de um por cento dos candidatos masculinos. Contudo, a mesma proporcionalidade se observa quanto as candidatas mulheres, considerando que houve reprovação de mais 17 delas, o que equivaleria a $23 \%$ do total de participantes do teste de barra fixa. VIII. Da análise é inquestionável que o teste de barra fixa dinâmica revela gritante inconstitucionalidade, de sorte que tal critério se mostra discriminatório, pois impede a isonomia de gênero no concurso posto em análise”.

O ultimo caso versa sobre um Recurso Ordinário de n 0160700-92.2012.5.17.0013 proveniente da comarca de Vitória/ES, julgado em 14 de maio de 2015 pela $2^{a}$ Turma do Tribunal Regional do Trabalho da $17^{\text {a }}$ Região, sob a relatoria da Desembargadora Wanda Lúcia Costa Leite França Decuzzi ${ }^{9}$. A ora recorrente inconformada com a decisão que julgou procedente os pedidos do autor tenta a reforma da mesma para afastar a responsabilidade quanto ao pedido de assédio moral.

Em breve síntese, o recorrido (autor) teve o pedido de assédio moral concedido, em razão de ter sido contratado para a função de piloto de jumbo na vaga destinada à cota para deficientes físicos, por ser portador de lesão definitiva no membro inferior decorrente de acidente automobilístico ocorrido em 1999 e que logo após ser admitido na empresa, passou a ser alvo de discriminação dentro da empresa, inclusive sendo perseguido por seu superior imediato. Dessa feita, a relatora aduz que "para assegurar o exercício pleno e equitativo dos direitos humanos e liberdades fundamentais por todas as pessoas com deficiência e promover o respeito pela sua dignidade inerente, torna-se imperioso conferir mecanismos capazes de assegurar real paridade de oportunidades entre os trabalhadores, imprimindo-se ações afirmativas com vistas a atingir a igualdade efetiva de tratamento entre os trabalhadores deficientes e os demais empregados" (fl. 22).

Restam demonstrado que as ações afirmativas são meios viáveis para suprir as desigualdades, bem como, a legitimidade do Poder Judiciário perante tais ações com o bojo de dar proporcionalidade e adequação ao caso concreto. Não se discute mais a constitucionalidade das ações afirmativas, posto que seja aferida por um complexo de proporcionalidade, onde há resolução de colisões entre os princípios constitucionais. Ademais, tais políticas tem o condão de promover a igualdade de oportunidade para todos, o que não legitima a desigualdade, só efetiva suas causas.

\section{Considerações finais}

O Brasil traça em rumo à institucionalização do Estado Democrático de Direito, onde se tenha uma boa parcela de participação da sociedade civil e grande democratização a fim de se efetivar os direitos sociais. Diante disso, a globalização vem com o

9 Recurso Ordinário no 0160700-92.2012.5.17.0013. [consultado em 2021-04-30]. Disponível em: https://www.trtes.jus.br/principal/publicacoes/leitor/474957558?formato=pdf. 
intuito de criar mecanismos para o crescimento do país, seja na forma econômica e política, seja na ordem jurídico constitucional.

Destarte, a globalização trouxe situações que dependem de normas para serem asseguradas, e da criação de políticas públicas em conjunto com o Poder Judiciário para que sejam aplicadas. É o caso dos direitos sociais, dispostos no artigo $6^{\circ} \mathrm{da}$ Constituição Federal da República Federativa do Brasil, os quais se encontram regulamentados no texto normativo, mas dependem de uma política pública para sua efetividade. Bem como, dos direitos que necessitam de uma ação afirmativa para que sejam contemplados com igualdade de oportunidades, que é o caso das reservas vagas para pessoas com deficiência, baixa renda, negros, em concursos e ensino, por exemplo. Dessa forma, o tratamento deve ser diferenciado para que seja propiciado a maior igualdade entre os desiguais.

Dessa maneira, o Poder Judiciário entra como instituidor e regente dessas políticas, pois ainda há muita desigualdade na sociedade brasileira, conforme análise dos casos jurisprudenciais envolvendo as matérias. Portanto, o desafio deste poder é encontrar espaços para concretizar os direitos humanos e sociais de bem estar em suas decisões.

Assim, conclui-se que o Estado e o Poder Judiciário, atuando em conjunto e exercendo papéis de gestores, podem construir um direito que se apresente através de uma linguagem aberta, que envolva os diversos níveis comunitários, promovendo a harmonia social, a cidadania, e garantindo a dignidade humana e os direitos humanos. 